\title{
Spectral Albedo in Bifacial Photovoltaic Modeling: What can be learned from Onsite Measurements?
}

Riedel-Lyngskar, Nicholas; Ribaconka, Martynas; Po, Mario; Thorsteinsson, Sune; Thorseth, Anders; Dam-Hansen, Carsten; Jakobsen, Michael L.

\section{Published in:}

Proceedings of $48<$ sup $>$ th $</$ sup $>$ IEEE Photovoltaic Specialists Conference

Link to article, DOI:

10.1109/PVSC43889.2021.9519085

Publication date:

2021

Document Version

Peer reviewed version

Link back to DTU Orbit

Citation (APA):

Riedel-Lyngskar, N., Ribaconka, M., Po, M., Thorsteinsson, S., Thorseth, A., Dam-Hansen, C., \& Jakobsen, M. L. (2021). Spectral Álpedo in Bifacial Photovoltaic Modeling: What can be learned from Onsite Measurements? In Proceedings of 48 IEEE Photovoltaic Specialists Conference (pp. 0942-0949). IEEE. https://doi.org/10.1109/PVSC43889.2021.9519085

\section{General rights}

Copyright and moral rights for the publications made accessible in the public portal are retained by the authors and/or other copyright owners and it is a condition of accessing publications that users recognise and abide by the legal requirements associated with these rights.

- Users may download and print one copy of any publication from the public portal for the purpose of private study or research.

- You may not further distribute the material or use it for any profit-making activity or commercial gain

- You may freely distribute the URL identifying the publication in the public portal 


\title{
Spectral Albedo in Bifacial Photovoltaic Modeling: What can be Learned from Onsite Measurements?
}

\author{
Nicholas Riedel-Lyngskær ${ }^{1}$, Martynas Ribaconka ${ }^{1}$, Mário Pó ${ }^{2}$, Sune Thorsteinsson ${ }^{1}$, Anders Thorseth ${ }^{1}$, \\ Carsten Dam-Hansen ${ }^{1}$, Michael L. Jakobsen ${ }^{1}$ \\ ${ }^{1}$ Technical University of Denmark, Department of Photonics Engineering, Roskilde, Denmark \\ ${ }^{2}$ EKO Instruments B.V., The Hague, the Netherlands
}

\begin{abstract}
This contribution reports on a yearlong spectral albedo measurement campaign performed in Roskilde, Denmark. Four albedo scenarios are monitored using three sensor types. The ground surfaces include green grass, dry grass, gravel, and snow - all of which have been monitored with albedometers based on spectroradiometers, silicon-pyranometers, and thermopile pyranometers. Implications of using the various albedo data sources/assumptions in bifacial PV modeling are assessed with the spectrally weighted bifacial energy gain (BEG). We find that BEG differs by as much as $3 \%$ with the different albedo sensors and BEG can deviate by as much as $7 \%$ from the ground truth when an incorrect static spectral albedo assumption is used. Finally, the spectral mismatch factor (SMM) is calculated to summarize rear plane of array (POA) spectral shifts. Our measurements show midday backside POA spectral shifts as high as $\mathbf{2 5 \%}$ for Silicon bifacial PV devices mounted on single axis trackers above grass.
\end{abstract}

Keywords-Albedo, Spectrum, Bifacial, Photovoltaic, Tracker

\section{INTRODUCTION}

The albedo of a surface is defined as the percentage of incident sunlight that it reflects. The albedo of natural and synthetic materials is known to vary as a function of wavelength, but most photovoltaic (PV) simulation tools to date do not incorporate the spectral properties of albedo into their algorithms. This is because ground reflected irradiance constitutes less than $2 \%$ of the total frontside plane-of-array (POA) irradiance for most traditional monofacial installations (i.e., an array tilt angle from horizontal $\leq 30^{\circ}$ and albedo $\leq 0.25$ ). However, ground reflected irradiance contributes significantly to the energy produced by bifacial PV systems because the rear POA irradiance is comprised primarily of ground reflected light. With the rapid increase in bifacial PV module adoption - and the forecasted majority market share of bifacial cells by 2023 [1] - a better understanding of spectral albedo in bifacial PV applications is necessary to improve performance modeling accuracy and reduce perceived risk by investors.

Previous works on spectral albedo in bifacial PV applications come to a common conclusion that spectral effects must be accounted for in bifacial PV simulation [2] - [5]. A shortcoming of these and other works [6] - [8] is that they use a single spectral albedo curve (with the exception of [5]) for timeseries simulations when it is well-known that the spectral albedo distribution changes with conditions such as solar angle,

This work was funded by the Danish Energy Technology Development and Demonstration Program (EUDP) under project contract 64018-0624. sky diffuse fraction, surface roughness and surface moisture content [9]. We use continuous spectral albedo measurements and $2 \mathrm{D}$ view factor modeling to put the constant spectral albedo assumption under a microscope. Additionally, we analyze the differences in modeled rear POA irradiance $\left(G_{P O A, R e a r}\right)$ and bifacial gain that can occur due to different albedo data sources, which in this work include:

1. Measured spectral albedo from spectroradiometers,

2. Measured broadband albedo from pyranometers,

3. Measured broadband albedo from Si-pyranometers,

4. Constant spectral albedo from data base, and

5. Constant albedo assumption of 0.2 .

Our previous work demonstrated that $\mathrm{G}_{\mathrm{POA} \text {,Rear }}$ modeling contributes approximately $0.5 \%$ uncertainty to annual energy yield estimates when using state-of-the-art bifacial PV simulation tools [10]. A motivation of the present work is to identify approaches that can reduce this uncertainty.

\section{METHODS}

\section{A. Field Measurements}

Spectral irradiance data in the range of $300-1100 \mathrm{~nm}$ are recorded every five minutes by three EKO MS711 spectroradiometers. Two MS711s are horizontally mounted: one upward facing instrument records the global horizontal spectral irradiance $\mathrm{GHI}_{\lambda}$ and one downward facing instrument records the ground reflected horizontal spectral irradiance $\mathrm{RHI}_{\lambda}$ (Fig. 1). The third MS711 records the direct normal spectral irradiance $\mathrm{DNI}_{\lambda}$. This instrument is installed on a dual-axis tracker and has a $5^{\circ}$ field-of-view (FOV) collimation tube - as used in [11]. The spectral albedo $\alpha_{\lambda}$ is calculated as the ratio of the downward facing $\mathrm{RHI}_{\lambda}$ and upward facing $\mathrm{GHI}_{\lambda}$ measurements:

$$
\alpha(\lambda)=\frac{R H I(\lambda)}{G H I(\lambda)}
$$

The diffuse horizontal spectral irradiance $\mathrm{DfHI}_{\lambda}$ is calculated (2) from the difference between the measured $\mathrm{GHI}_{\lambda}$ and the measured $\mathrm{DNI}_{\lambda}$ adjusted by Lambert's cosine law with the zenith angle $\left(\theta_{\mathrm{Z}}\right)$ :

$$
D f H I(\lambda)=G H I(\lambda)-D N I(\lambda) \cdot \cos \theta_{Z}
$$


The field measurement campaign investigates the diurnal and seasonal variations in spectral albedo under four surfaces/conditions: green grass (Fig. 1a), dry grass (Fig. 1b), gravel (Fig. 1c), and snow (Fig. 1d). Broadband albedo measurements from Class $\mathrm{C}$ thermopile pyranometers and Silicon-photodiode pyranometers are acquired onsite at 1minute intervals. The pyranometers albedo stand is located $12 \mathrm{~m}$ from the spectral albedo setup and the Si-Pyranometer albedo stand is located $\sim 100 \mathrm{~m}$ away.

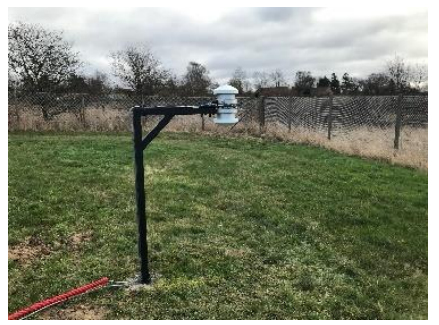

(a)

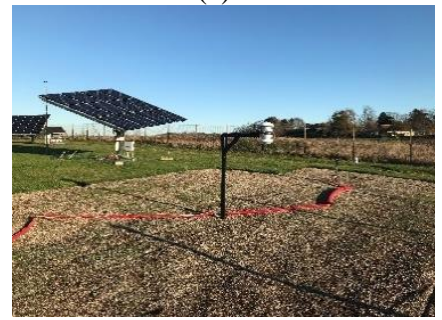

(c)

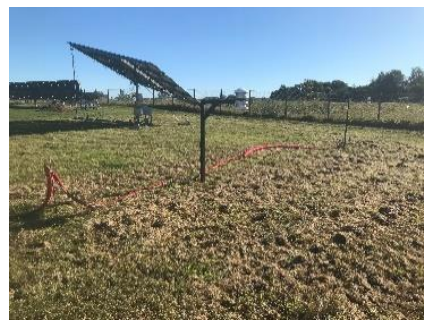

(b)

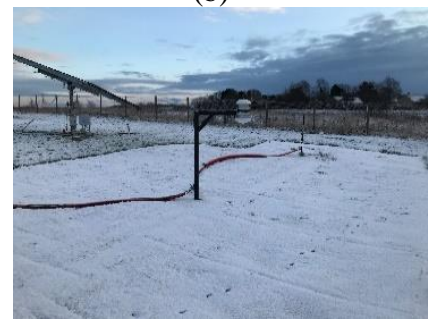

(d)
Fig. 1. Various albedo conditions tested: (a) Healthy grass from Feb - May 2020, (b) dry grass from Jul - Sep 2020, (c) 5 - 8 mm gravel from Sep 2020 Apr 2021, and (d) snow in Jan 2021.

\section{B. Laboratory Calibration and Uncertainty}

Calibration of all three EKO MS711 spectroradiometers was performed inhouse at DTU Fotonik's DOLL laboratories in January 2020 just before the field measurement campaign began. The calibration setup consists primarily of a NIST traceable FEL lamp on an alignment jig $50 \mathrm{~cm}$ from the device under test with measures to mitigate stray light. A second measurement of the FEL reference lamp was performed in May 2021 immediately after the measurement campaign concluded. These final measurements served to check for any calibration and/or wavelength drifts that occurred during the field measurements. The spectroradiometers used for $\mathrm{DNI}_{\lambda}$ and $\mathrm{GHI}_{\lambda}$ measurements deviated by less than $5 \%$ relative to the reference lamp between 400 and $1050 \mathrm{~nm}$ and showed mean bias errors (MBE) less than 3\%. The spectroradiometer used for $\mathrm{RHI}_{\lambda}$ measurements showed deviations as high as $9 \%$ at some wavelengths, but the MBE was 3\%, comparable to the other two spectroradiometers. This instrument showed pronounced wavelength shifts at 645 and $670 \mathrm{~nm}$, which were not observed in the other two instruments.

The expanded calibration uncertainty is wavelength and instrument dependent. Fig. 2 shows the calibration uncertainty during the May 2021 calibration event. The uncertainty is estimated using uncertainty contributions from: lamp sensor distance $(0.8 \%$ ), signal to error estimation (mean $2.2 \%$, max $8 \%)$, lamp current stability $(0.1 \%)$, lamp drift estimate $(0.5 \%)$, repeatability of measurement $(0.5 \%)$ and readout noise (max $2.2 \%)$.

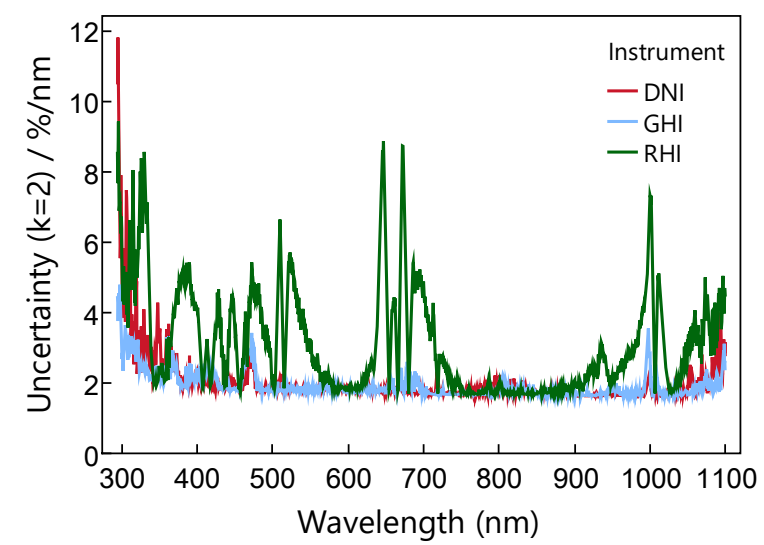

Fig. 2. Measurement uncertainty $(k=2)$ of the spectral calibration. The spikes are appearing where gradients in the spectral throughput cause responsivity to change drastically with wavelength shifts.

The angular response of the upward and downward facing MS711s follow a cosine response within 3\% or better when the solar zenith angle is greater than $80^{\circ}$. This cosine error will primarily affect the upward facing (GHI) instrument at high solar zenith angles in direct sunlight.

\section{Handling of Spectral Data}

The upward and downward facing spectroradiometers do not acquire measurements in parallel because a single datalogger records data from both units. We have observed up to $\sim 15$ second delays between when the first spectroradiometer begins its measurement and when the second unit completes its measurement. This delay is due to the data processing time in the logger and the exposure times in each sensor, which take 10 to $5000 \mathrm{~ms}$ each depending on the light intensity. An irradiance stability check is needed because the calculated spectral albedo values assume a constant condition during the $\mathrm{GHI}_{\lambda}$ and $\mathrm{RHI}_{\lambda}$ measurements. The stability check is performed for each measurement using a variability index (VI) [12]. GHI data recorded every 10 seconds by a Class A pyranometer are used to calculate a VI within a 2-minute period: approximately 1 minute before and after the measurement. Measurements are removed when the VI $>1$.1. Data recorded on detector edges $(\lambda$ $<300 \mathrm{~nm}$ and $\lambda>1050 \mathrm{~nm}$ ) are also removed as they are often prone to measurement noise.

The bifacial cells studied in this work are spectrally sensitive to light between 300 and $1200 \mathrm{~nm}$. Since the useful detector range is limited to $1050 \mathrm{~nm}$, the spectral irradiance gap (1050 $1200 \mathrm{~nm}$ ) is completed using SMARTS 2.9.5 [13]. We use the real-time solar zenith angle (air mass proxy), ambient temperature and atmospheric pressure to generate SMARTS clear sky spectra that correspond to each spectral measurement. The simulated clear sky spectra are scaled using a procedure described by [14], which uses the broadband global and diffuse fluxes to account for cloud cover. The $\mathrm{RHI}_{\lambda}$ data are extended by scaling the SMARTS spectral albedo file that shows the most similar relative profile to the measurements. For example, the spectral albedo measurements of grass are extended using the 'GrazingField.dat' file. The spectral extension carries minimal effect on the results, however, because the spectral responsivity is low between 1050 and $1200 \mathrm{~nm}$, and because sunlight can be 
significantly absorbed by atmospheric water vapor between 1100 and $1200 \mathrm{~nm}$.

Handling of continuous solar spectral measurements can be challenging owing to the sheer volume of data generated over yearly timescales. For example, our three spectroradiometers with 2048 pixels each measuring every 5 minutes over 15 months generated a data frame with over 22 million rows. We have found the hierarchical data format (HDF5) to be particularly useful in organizing and working with such datasets.

\section{Optical Model}

The measured and calculated spectral irradiance data $\left(\alpha_{\lambda}\right.$, $\mathrm{GHI}_{\lambda}, \mathrm{DNI}_{\lambda}$, and $\mathrm{DfHI}_{\lambda}$ ) are passed to the open-source Pythonbased 2D view factor model pvfactors [15] running in full simulation mode. Two principal assumptions inherent in 2D view factor models are that surfaces scatter light isotropically (i.e., Lambertian scattering) and that the PV rows are infinitely long (i.e., edge brightening effects are ignored). Most natural surfaces, however, are non-Lambertian scatterers, at least to some extent.

With pvfactors, we calculate the front and rear POA spectral irradiances $\left(\mathrm{G}_{\mathrm{POA}, \text { Front }, \lambda}\right.$ and $\left.\mathrm{G}_{\mathrm{POA}, \mathrm{Rear}, \lambda}\right)$ for $25^{\circ}$ fixed-tilt and horizontal single-axis tracking (SAT) systems (Table 1), which are the two types of large-scale bifacial PV systems collocated at the site [10]. In both cases, a five-row system is simulated and results from the middle row are reported.

Table 1. Configuration of the 2-in-portrait bifacial PERC systems installed on site and modeled in this work. Systems are installed above grass (see Fig. 1a)

\begin{tabular}{|c|c|c|}
\hline & Fixed-Tilt & $\begin{array}{c}\text { Single Axis } \\
\text { Tracker }\end{array}$ \\
\hline Tilt Angle & $25^{\circ}$ & $\pm 60^{\circ}$ \\
\hline Hub (center) Height $(\mathrm{m})$ & 2.3 & 2.0 \\
\hline Ground Cover Ratio & 0.40 & 0.28 \\
\hline
\end{tabular}

The spectral irradiance data at each wavelength $\lambda$ are processed in pvfactors using the same approach as if broadband irradiance data were used. In other words, instead of passing broadband irradiance in $\mathrm{W} \cdot \mathrm{m}^{-2}$, as a pvfactors user would do ordinarily, our implementation passes spectral irradiance in $\mathrm{W} \cdot \mathrm{m}^{-2} \cdot \mathrm{nm}^{-1}$. The model then accounts for the interreflections between scene surfaces using spectrally resolved light for wavelengths between 300 and $1200 \mathrm{~nm}$. Front and rear side angular reflection losses are accounted for using the Sandia incident angle modifier (IAM) model [16].

\section{E. Analysis}

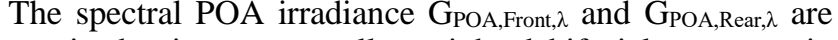
summarized using a spectrally weighted bifacial energy gain (BEG), which is calculated as:

$$
B E G=\frac{\int_{a}^{b} S R_{\text {Rear }}(\lambda) \cdot G_{P O A, \text { Rear }}(\lambda) d \lambda}{\int_{a}^{b} S R_{\text {Front }}(\lambda) \cdot G_{\text {POA,Front }}(\lambda) d \lambda} \cdot 100 \%
$$

Where $\mathrm{SR}_{\text {Front }}$ and $\mathrm{SR}_{\text {Rear }}$ are the PV cell's spectral response of the front and backside. The integration limits $a$ to $b$ are 300 to $1200 \mathrm{~nm}$. The BEG in (3) is simply the ratio of short-circuit current $\left(\mathrm{I}_{\mathrm{SC}}\right.$ ) generated by the backside relative to the $\mathrm{I}_{\mathrm{SC}}$ generated by the frontside. This equation does not include adjustments for structural shading on the backside of the array, or any possible thermal differences between monofacial and bifacial cells that could affect voltage. Nonetheless, (3) is still useful for our objective, which is to understand the differences in bifacial gain that can occur due to different albedo data sources. In the case of the Si-pyranometer and pyranometer measured albedo, the albedo passed to pvfactors is the same at all wavelengths, proportional to the measurements at each timestamp (i.e., a 'flat' spectral albedo curve is produced). In the case of constant spectral albedo data, the data originates from the ASTER library [17], which is the source of the spectral albedo files in SMARTS used here. In all cases, the same $\mathrm{DNI}_{\lambda}$ and $\mathrm{DfHI}_{\lambda}$ spectra are input to pvfactors.

The Results section also reports backside POA spectral mismatch (SMM) factors (4). Equation (4) is taken from (7) in IEC 60904-7 [18], where $G_{R e f}$ is the AM1.5G reference spectrum defined in IEC 60904-3 [19].

$$
S M M=\frac{G_{\text {Ref }} \cdot \int_{a}^{b} S R_{\text {rear }}(\lambda) \cdot G_{P O A, \text { rear }}(\lambda) d \lambda}{G_{P O A, \text { rear }} \cdot \int_{a}^{b} S R_{\text {rear }}(\lambda) \cdot G_{\text {Ref }}(\lambda) d \lambda}
$$

The SMM factor captures spectral shifts relative to the AM1.5G rating wherein SMM > 1 indicates spectrally induced $\mathrm{I}_{\mathrm{SC}}$ gains and $\mathrm{SMM}<1$ indicates spectrally induced $\mathrm{I}_{\mathrm{SC}}$ losses. The backside SMM also serves as a meaningful way to summarize the large amount of spectral albedo data recorded.

The BEG and SMM are calculated for a standard bifacial ptype passivated emitter and rear contact (PERC) cell. The PERC cell was procured from Blue Sun solar and encapsulated in $3 \mathrm{~mm}$ PV glass and EVA at DTU. Fig. 3 shows the measured spectral responsivity on front and backside. The choice to analyze PERC was made because this technology is presently the most common bifacial cell type deployed in large systems.

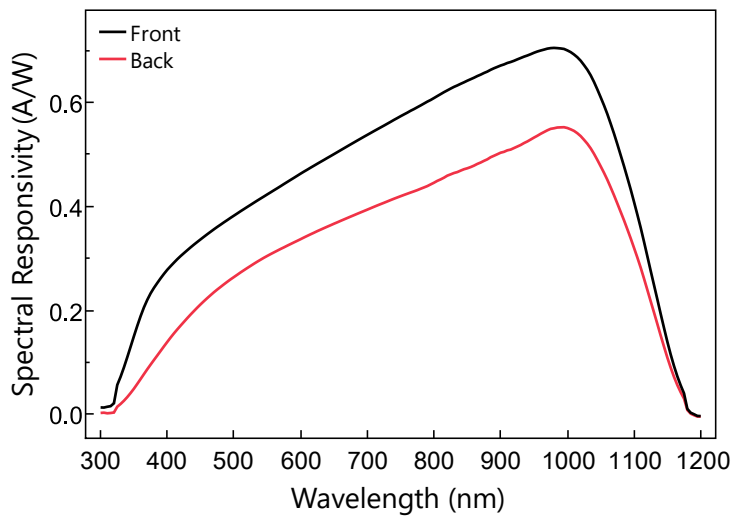

Fig. 3. Absolute spectral responsivity of the PERC cell (front and back). The cell is encapsulated in standard PV glass and measured using a PV Measurements OEXL quantum efficiencv measurement svstem.

\section{RESULTS}

\section{A. Diurnal and Seasonal Spectral Albedo}

Fig. 4, Fig. 5, and Fig. 6 show spectral albedo measurements recorded on clear sky days above green grass, dry grass, and gravel, respectively. Note that the sky conditions in the pictures 
shown in Fig. 1 do not represent those during the measurements in Fig. 4 to Fig. 6, but the ground conditions are essentially the same. As there were no sunny days when snow cover was recorded, a $100 \%$ diffuse day is shown for the daily snow spectral albedo in Fig. 7. The histogram borders in each plot show the daily density of spectral albedo measurements in the range of 300 to $1050 \mathrm{~nm}$. The red reference lines within the histograms show the daily mean spectral albedo.

In instances where the spectral albedo curve is smooth (e.g., Fig. 6 and Fig. 7), we observe kinks (e.g., at $675 \mathrm{~nm}$ ) which are measurement artifacts that were not present immediately after the calibration in January 2020. The fact that these kinks occurred after less than 1 year of deployment demonstrates how sensitive the alignment of the internal optical bench (i.e., mirrors and grating) is to field conditions and highlights the need for regular calibration.

The clear sky measurements demonstrate that there are notable shifts in spectral albedo over the course of a day. Specifically, there is a minimum spectral albedo around solar noon when the sun elevation is at its peak. The color gradient in the plots highlights this solar zenith dependency. The clear sky solar zenith dependency, with its early morning and late afternoon peaks, is of course typical of broadband albedo measurements [20]. In the case of spectral albedo measurements, however, the solar zenith dependency is not equal across all wavelengths. The tendency is for near infrared (NIR) wavelengths to show greater solar zenith dependency than visible (VIS) or UV wavelengths. This is because the spectral distribution of the sun's beam component shifts toward NIR wavelengths in the morning and afternoon, and because some surfaces reflect more NIR light than UV or VIS (e.g., grass).

A comparison between Fig. 4 and Fig. 5 reveals the seasonal spectral albedo variations going from spring into summer, and a comparison to Fig. 7 demonstrates the dramatic shifts that can occur in winter. If previous works [2] - [5] are correct in that spectral albedo ought to be implemented in bifacial PV modeling, then the seasonal shifts shown here offer scenarios where onsite measurements could advise a performance model that uses spectral albedo data.

One or more spectral albedo curves from SMARTS are shown in Fig. 4 to Fig. 7. When spectral albedo is accounted for in PV modeling (e.g., [6] - [8], [21], [22]) such static assumptions are used, almost exclusively. One unsurprising take away from comparing the measurements to static assumptions is that the static spectral albedo curves often fail to agree with the measured albedo curves' shape and magnitude across all wavelengths. In other words, static spectral albedo assumptions are not likely to be physically correct. The SMARTS documentation indicates that for all materials except snow, the spectral albedo curves were measured at a solar zenith angle of about $53^{\circ}$.

The largest differences between measurements and the database assumption occur in the VIS region of Fig. 5. (Dry grass). This is likely because the grass at the site retained some chlorophyl (visible in the greenness of Fig. 1b), even during the driest summer period.

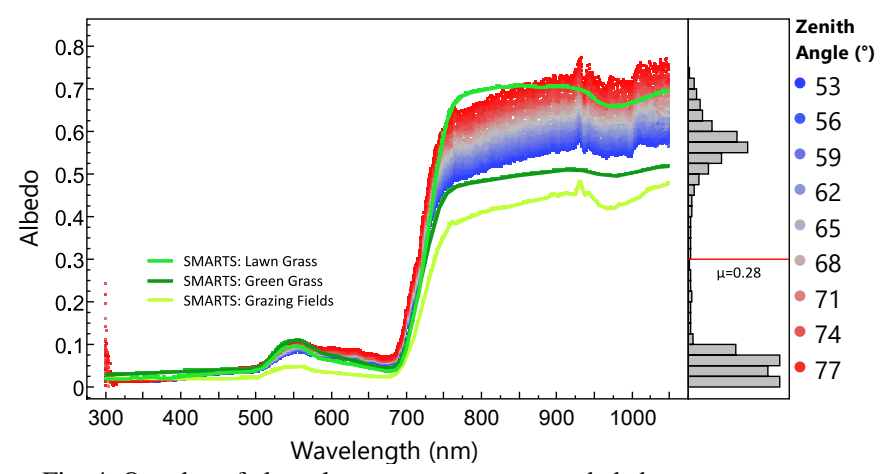

Fig. 4. One day of clear sky measurements recorded above green grass (25.03.2020). Three of the most similar SMARTS albedo curves are shown.

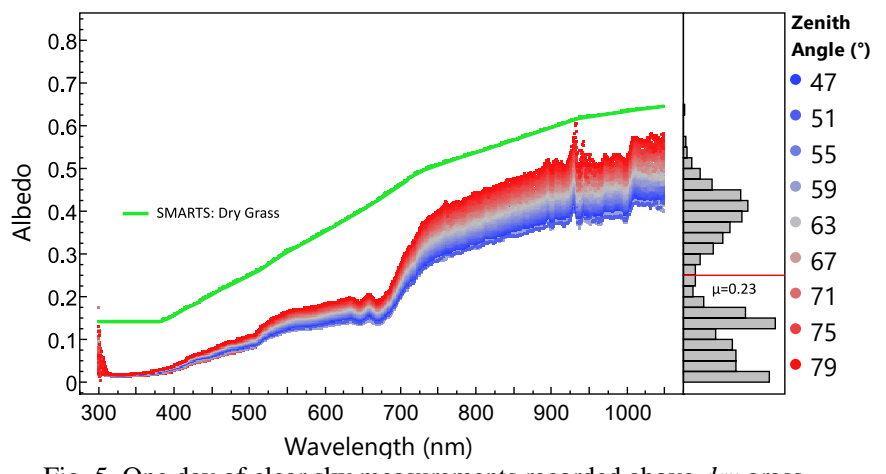

Fig. 5. One day of clear sky measurements recorded above dry grass (31.08.2020). The most similar SMARTS spectral albedo is also shown.

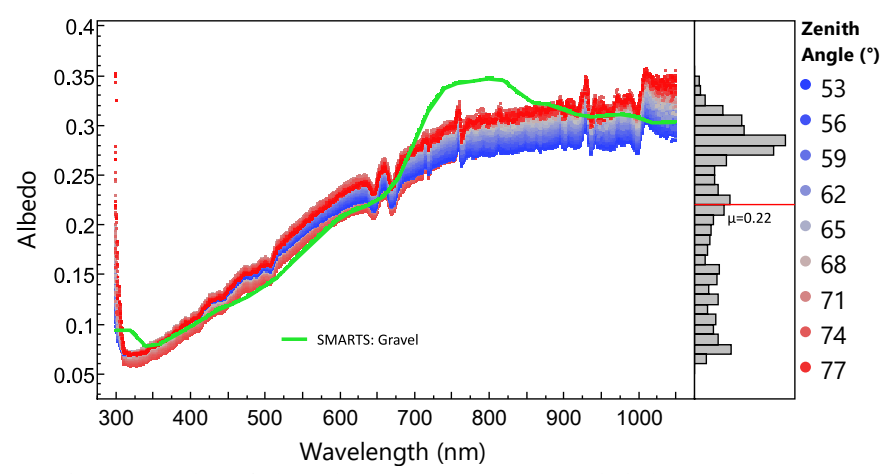

Fig. 6. One day of clear sky measurements recorded above gravel (18.09.2020). The most similar SMARTS albedo is also shown.

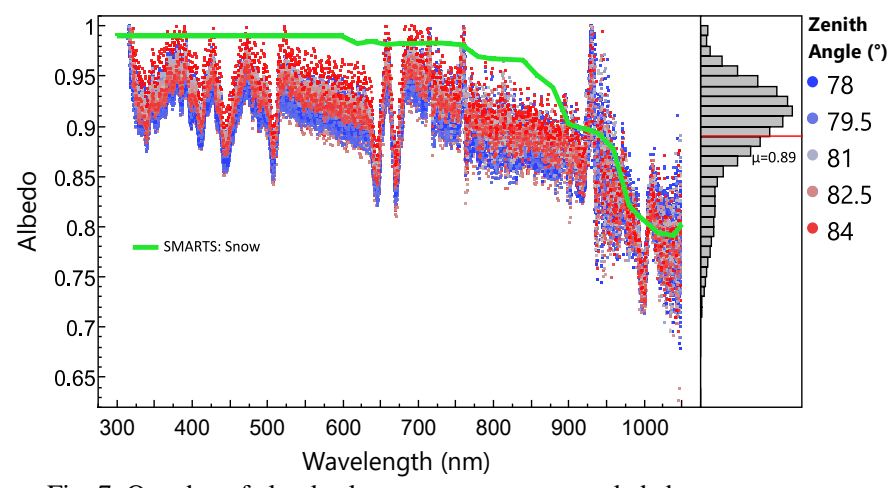

Fig. 7. One day of cloudy sky measurements recorded above snow (06.01.2021). The most similar SMARTS is also shown. 
In the gravel albedo case, the spectral albedo from SMARTS aligns well to the measurements for all wavelengths except 700 - $900 \mathrm{~nm}$. The differences in this spectral region are likely because the mineral content of the onsite gravel mixture deviates from that of the database assumption. For example, iron content is known to absorb solar radiation between 900 and $1000 \mathrm{~nm}$ [23], but the reasons for the discrepancy at $700-900 \mathrm{~nm}$ remain unclear.

Finally, the measured snow albedo case is shown in Fig. 7. The spectral albedo of snow is complex as it not only depends on solar zenith angle and diffuse ratio, but it also depends on the snow's freshness (age), grain size (roughness), snow depth, and whether the surface below the snow can be seen (coverage) [24]. Based on local weather measurements, we estimate that the snow depth during the measurements in Fig. 7. was less than 5 $\mathrm{cm}$, that the snow fell within 24 hours of measurement, and that the gravel below was completely covered by snow. A particular challenge of snow albedo measurements is that the upward facing instrument will become covered in snow without some form of sensor heating or ventilation. The spectroradiometers used here contain thermoelectric cooling elements to maintain a detector temperature of $25^{\circ} \mathrm{C} \pm 0.5^{\circ} \mathrm{C}$, which subsequently melts any snow deposited on the instruments. The SMARTS documentation indicates the spectral albedo files for snow are recorded at a zenith angle of about $20^{\circ}$, but in principle, the solar zenith angle should have very little effect on the albedo during a $100 \%$ diffuse day like the one shown.

\section{B. Bifacial Gain with Different Albedo Data Sources}

Fig. 8, Fig. 9, Fig. 10 show modeled bifacial gains for PERC on fixed tilt and tracked systems above green grass, dry grass, and gravel, respectively. Each figure shows the variability of modeled bifacial gain using five albedo data sources. The diamonds within each box plot show the $95 \%$ confidence interval of the mean, which are small because of the large number of observations. Recall that the pyranometer, Sipyranometer and spectroradiometer albedo data are continuous measurements whereas the constant albedo (0.2) and SMARTS spectral albedo do not change with time. The duration of each albedo scenario is two, four and eight months for dry grass, green grass, and gravel, respectively.

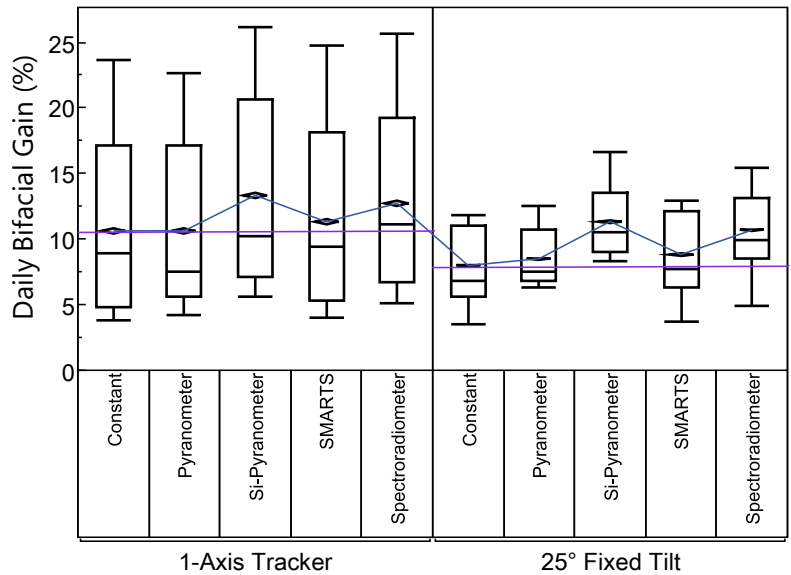

Fig. 8. Variability of simulated bifacial gain during the four month green grass albedo period using five different albedo data sources. The horizontal purple lines show the measured bifacial gain on large-scale PERC systems above grass during the same period. The SMARTS spectral file used is 'GrazingFields.dat'.

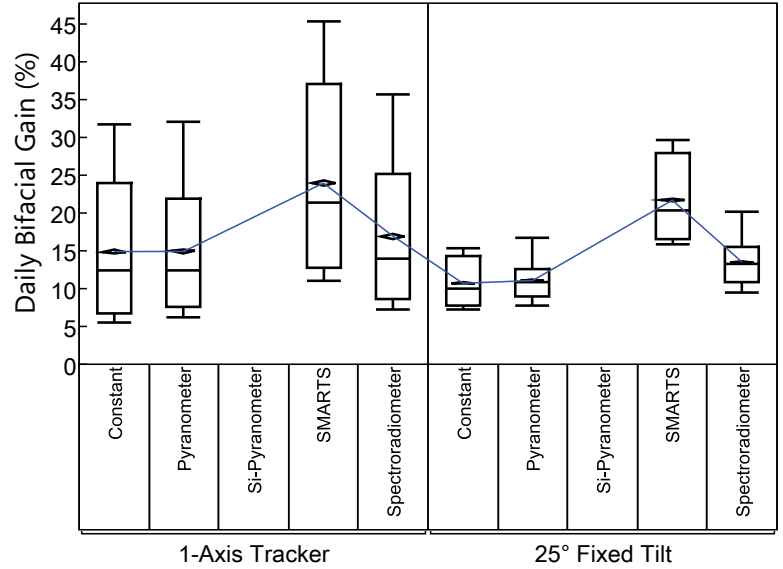

Fig. 9. Simulated bifacial gain results for the two month dry grass albedo period using four different albedo data sources. The Si-Pyranometer results are not shown because the ground surface under this sensor was not comparable to the others during this time. The SMARTS spectral file used is 'DryGrass.dat'.

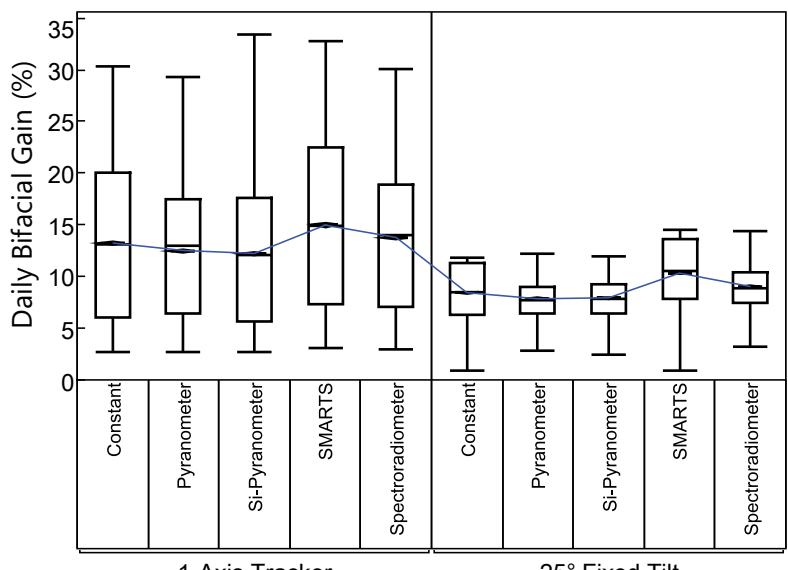

Fig. 10. Simulated bifacial gain results for the five month gravel albedo period using five different albedo data sources. The SMARTS spectral file used is 'Gravel.dat'.

In the green grass and gravel albedo cases shown Fig. 8 and Fig. 10, we see that the five albedo data sources cause the simulated bifacial gain to change by as much as $3 \%$. In the dry grass albedo case shown in Fig. 9, the range of modeled bifacial gain values is $10 \%$. The larger range of bifacial gains in the dry grass simulations is primarily caused by the SMARTS spectral albedo that results in $7 \%$ higher bifacial gain than when measured spectral albedo are used. Clearly, the SMARTS 'drygrass.dat' file is not a good approximation of the dry grass albedo, at this location (see Fig. 5).

In the green grass and gravel albedo cases, the bifacial gain changes by about $1.5 \%-2.0 \%$ if continuous spectral albedo measurements or SMARTS spectral albedo are used. Grazing Fields SMARTS albedo was used in the grass case because its relative shape was a near match to our measurements, thus leading us to believe that this vegetation was of a similar or same genus and species as the grass onsite. We also ran the simulations using the 'LawnGrass.dat' and 'GreenGrass.dat' SMARTS files. We found that bifacial gain was $7 \%$ higher and $1 \%$ lower, respectively, than when spectral albedo measurements were used. 
Notable in the green grass albedo case of Fig. 8 is the bifacial gain calculated with Si-pyranometer albedo data is about $3 \%$ higher than when calculated with pyranometer data. This positive bias can be explained by the large 'red shift' of the grass albedo spectrum relative to AM1.5G (see Fig. 4). It is well known that the output of Silicon devices calibrated under the AM1.5G spectrum will increase when exposed to red shifted spectra [25]. Hence, the albedo of vegetation will tend to be higher when measured by Si-pyranometers or reference cells than with pyranometers. Similar results were reported by [26].

Green grass albedo (Fig. 8) is the only condition where onsite measurements of large-scale monofacial and bifacial PERC systems are available. The mean bifacial gain of these systems during the four-month period are shown with horizontal purple lines. Curiously, the constant albedo assumption of 0.2 yields the best agreement to the measurements. However, a fair comparison of the model and measurement requires at least two adjustments: 1) the model would need to account for structural shade losses, and 2) the spectral responsivity used in the model would need to be of a full-size module (i.e., with junction boxes, frame etc.), not an individual cell. If such adjustments were implemented, we estimate that the bifacial gain in all simulations would be reduced by at least $1 \%$.

\section{Backside Spectral Mismatch}

Fig. 11 shows the backside spectral mismatch (SMM) of the PERC device during the four albedo periods studied on two structure types. We also calculated backside SMM for bifacial n-PERT and IBC cells, but because all devices are single junction silicon cells with similar bandgaps, the differences in SMM between the three devices were small $( \pm 0.01)$, likely within the uncertainty of the SMM calculation itself.

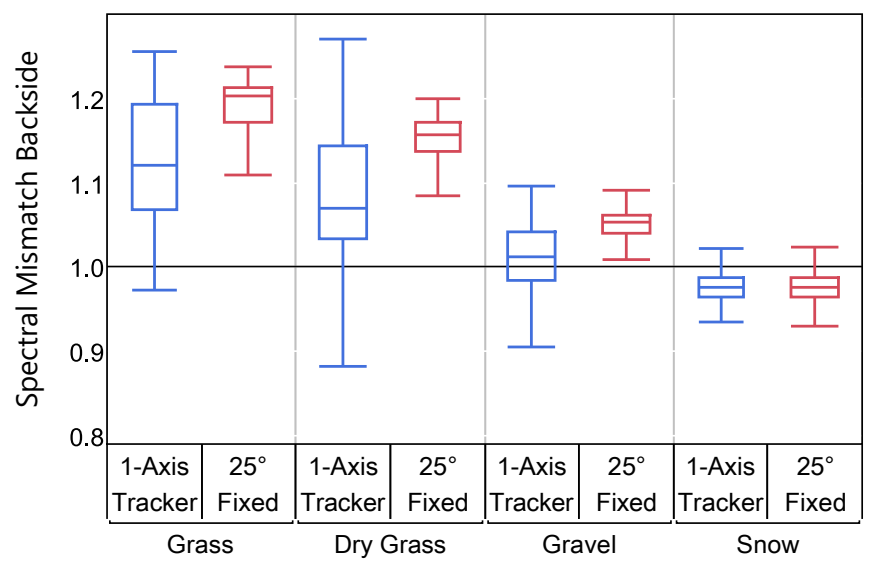

Fig. 11. Box and whisker plots showing spectral mismatch factors for the backside of the PERC cell on two structure types: trackers (blue), fixed (red). Mismatch is calculated for four albedo periods corresponding to Fig. 1.

The single axis tracker SMM results show a wider range of values than the $25^{\circ}$ fixed tilt SMM results. This is explained by the tracker's continuously changing tilt angles, which are steepest in the early morning and late afternoon $\left( \pm 60^{\circ}\right)$. The steeper the tilt angle, the greater the contribution of sky diffuse light to rear POA irradiance. For albedos that increase with wavelength (i.e., grass and gravel), backside tracker SMM always peaks midday. At midday, the tracker is horizontal, and the backside only receives reflected light from the ground. The green grass albedo has the largest red shift (i.e., ratio of NIR to VIS light) than the other three ground surfaces, which likely causes the highest SMM. The grass reflects more VIS light as it dries, which decreases the backside SMM by about 0.07 (7\%) at the end of summer.

The median backside SMM of the grass and dry grass albedos is between about 1.1 and 1.2. Although these SMM factors correspond to ISC gains of 10 to $20 \%$ relative to the AM1.5G rating, one must remember that frontside irradiance is approximately an order of magnitude greater than backside irradiance. Thus, performance models of bifacial systems above grass could suffer inaccuracies of 1-2\% if spectral albedo effects are not properly accounted for.

\section{Rear Plane-of-array (POA) Spectra}

Fig. 12 and Fig. 13 show discretized rear POA spectral irradiance $\left(\mathrm{G}_{\mathrm{POA}, \mathrm{Rear}, \lambda}\right)$ on the single axis tracker above green grass during the morning and afternoon of a cloudless day (25.03.2020). The $\mathrm{G}_{\mathrm{POA}, \mathrm{Rear}, \lambda}$ is simulated at 20 equally spaced segments, which correspond to the 20 vertical cell locations on the 2 -in-portrait tracker. Segment 1 is the western most cell and segment 20 is the eastern most cell.

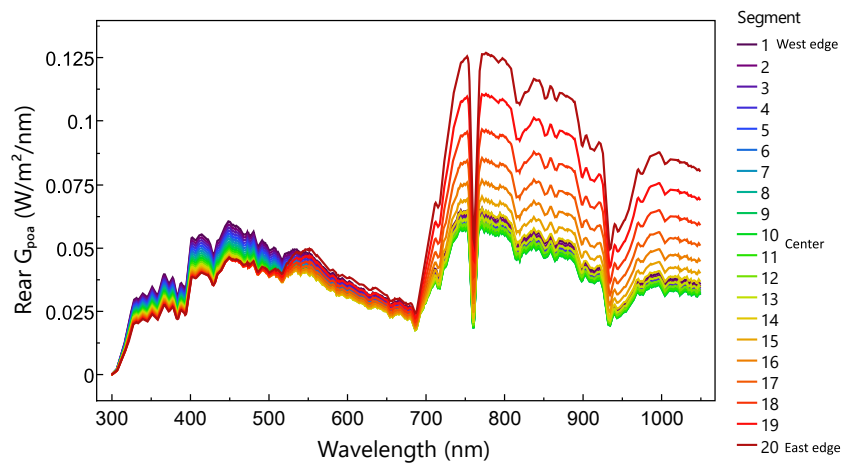

Fig. 12. Simulated rear spectral irradiance of the tracker system on a clear sky day in the morning at 20 discrete segments. At this time the tracker is tilted at $60^{\circ}$ from horizontal and facing east (surface azimuth $=90^{\circ}$ ).

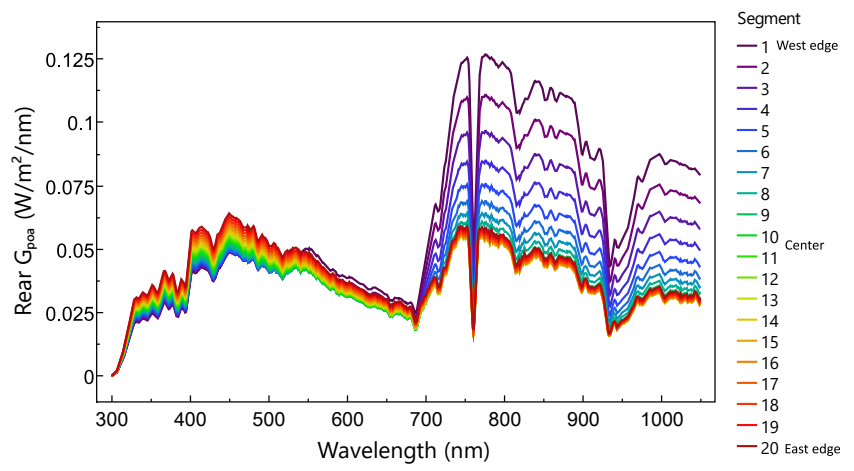

Fig. 13. Simulated rear spectral irradiance on the tracker system on a clear sky day in the afternoon at 20 discrete segments. At this time the tracker is tilted at $60^{\circ}$ from horizontal and facing west (surface azimuth $=270^{\circ}$ ).

The $20 \mathrm{G}_{\mathrm{POA}, \mathrm{Rear}, \lambda}$ spectra in Fig. 12 (morning) and Fig. 13 (afternoon) show mirrored trends. In the morning when the tracker is pointing east, segment 1 (west) is highest in the sky and segment 20 (east) is lowest to the ground. Thus, segment 1 receives the largest contribution of sky diffuse irradiance and segment 20 the largest contribution of ground reflected 
irradiance. In the afternoon, the height of the segments is reversed with 1 lowest to the ground and 20 highest in the sky.

Because the clear sky diffuse spectrum is blue shifted (due to Rayleigh scattering), and the green grass albedo is heavily red shifted (see Fig. 4), the western most and eastern most cells can see notably different spectral distributions in the morning and afternoon. This can cause the SMM within the array to vary by as much as $\pm 0.075(7.5 \%)$. Midday when the tracker is horizontal, the spectral distributions at the 20 segments are the same, and thus there is no SMM gradient at solar noon.

Fig. 14 shows $\mathrm{G}_{P O A, R e a r, \lambda}$ under the same clear sky and grass albedo conditions as in Fig. 13, but for the $25^{\circ}$ fixed tilt system. The GPOA,Rear, $\lambda$ is again simulated at 20 cell locations within the 2 -in-portrait array where segment 1 corresponds to the top most cell and segment 20 corresponds to the bottom most segment.

The backside light intensity is greater at the bottom than at the top of the fixed tilt system, but the relative spectral distribution among the 20 segments varies less than the 20 segments within the single axis tracker. This is because the top segment in the $25^{\circ}$ fixed tilt system receives less sky diffuse light than an array at $60^{\circ}$ as is the case in Fig. 12 and Fig. 13. So long as the sun is in front of the array, the backside SMM does not vary with solar position.

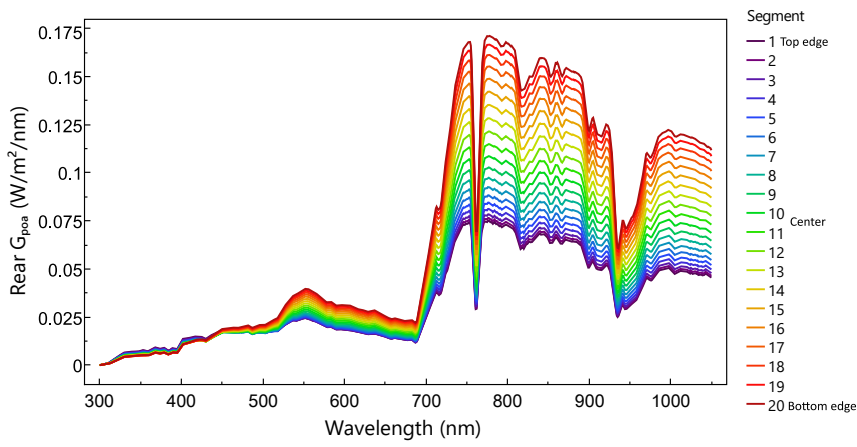

Fig. 14. Simulated rear spectral irradiance on the $25^{\circ}$ south facing fixed tilt system on a clear sky day in the afternoon at 20 discrete segments.

\section{DiscuSSION AND CONCLUSIONS}

Our measurements show that the albedo at bifacial PV sites can be highly spectrally dynamic over daily and seasonal timescales. The bifacial gains calculated with pyranometer, Sipyranometer and spectroradiometer albedo varied by as much as $3 \%$ for the systems and ground surfaces studied.

If spectral albedo from a database shall be used in a bifacial performance model, then detailed information about the ground's type and condition are required. For example, SMARTS 2.9.5 contains seven files for grass and the present ASTER (ECOSTRESS) library contains at least nine files classified as grass. Knowledge that the ground is simply 'grass' may not be sufficient: Additional information such as genus, species, water content and growth state is likely required to correctly select spectral albedo from a database. Differences in bifacial gain up to $7 \%$ were observed when the static spectral albedo curve was not representative of actual conditions.

The large backside spectral mismatch values of 1.1 to 1.2 lead us to recommend spectral albedo measurements in some capacity. The most basic solution to account for spectral albedo effects would be a rear POA reference cell, but a more robust method would be to sample the albedo at a few carefully selected wavelengths. Such down sampled measurements can be made without significantly affecting the results shown here because spectral albedo is not heavily structured like the sun spectrum.

\section{ACKNOWLEDGMENT}

We thank Dennis Corell of DTU for supporting the spectrometer calibration effort, Rasmus Nielsen of DTU for helping with the spectral responsivity measurements, and Dr. Joris Libal of ISC Konstanz for providing us with bifacial nPERT and IBC cell samples.

\section{REFERENCES}

[1] "International Technology Roadmap for Photovoltaics: 2020 Results," ITRPV, 2021.

[2] M. R. Vogt et al., "Impact of using spectrally resolved ground albedo data for performance simulations of bifacial modules," in $36^{\text {th }}$ EUPVSEC, Brussels, 2018.

[3] C. Monokroussos et al., "Rear-side spectral irradiance at 1 sun and application to bifacial module power rating," Progress in Photovoltaics, 2020 .

[4] M. Gostein, B. Marion and B. Stueve, "Spectral Effects in Albedo and Rearside Irradiance Measurement for Bifacial Performance Estimation," in 47th IEEE PVSC, Virtual, 2020.

[5] J. C. Blakesley et al., "Effective spectral albedo from satellite data for bifacial gain calculations of PV systems," in $38^{\text {th }}$ EUPVSEC, Virtual, 2020.

[6] R. Andrews and J. Pearce, "The Effect of Spectral Albedo on Amorphous Silicon and Crystalline Silicon Solar Photovoltaic Device Performance," Sol. Energy, vol. 91, pp. 233-241, 2013.

[7] M. P. Brennan et al., "Effects of spectral albedo on solar photovoltaic devices," Sol. Energy Mat. \& Sol. Cells, vol. 124, pp. 111-116, 2014.

[8] K. McIntosh et al., "Mismatch Loss in Bifacial Modules Due to Nonuniform Illumination in 1-D Tracking Systems," IEEE JPV, vol. 9, no. 6, pp. 1504-1512, 2019.

[9] J. Coakley, "Reflectance and Albedo, Surface," in Encyclopedia of Atmos. Sciences, 2003, p. 1914-1923.

[10] N. Riedel-Lyngskær et al., "Validation of Bifacial Photovoltaic Simulation Software," Applied Sciences, vol. 10, no. 23, pp. 1-29, 2020.

[11] N. Riedel et al., "Direct Beam and Diffuse Spectral Irradiance Measurements Analyzed With Average Photon Energy," in 7th WCPEC, Waikoloa, 2018.

[12] J. Stein, C. Hansen and M. Reno, "The Variability Index: A New and Novel Metric for Quantifying Irradiance and PV Output Variability," Sandia Report: SAND2012-2088C, 2012.

[13] D. Myers and C. Gueymard, "Description and availability of the SMARTS spectral model for photovoltaic applications," in SPIE \#5520, 2004.

[14] M. Ernst et al., "SunCalculator: A program to calculate the angular and spectral distribution of direct and diffuse solar radiation," Sol. Energy Mat. \& Sol. Cells, vol. 157, pp. 913-922, 2016.

[15] M. Anoma et al., "View Factor Model and Validation for Bifacial PV and Diffuse Shade on Single-Axis Trackers," in 44th IEEE PVSC, Washington D.C., 2017.

[16] D. King, B. Boyson and J. Kratochvill, "Photovoltaic Array Performance Model," Sandia Report (SAND2004-3535), 2004.

[17] A. Baldridge, S. Hook, C. Grove and G. Rivera, "The ASTER spectral library version 2.0," Remotes Sens Environment, vol. 113, p. 711-715, 2009.

[18] "IEC 60904-7 Ed. 4.0 (2019)". 
[19] "IEC 60904-3 Ed. 4.0 (2019)".

[20] B. Marion, "Measured and satellite-derived albedo data for estimating bifacial system performance," Sol. Energy, vol. 215, p. 321-327, 2021.

[21] T. C. R. Russel et al., "The Influence of Spectral Albedo on Bifacial Solar Cells: A Theoretical and Experimental Study," IEEE JPV, vol. 7, no. 6, pp. 1611-1619, 2017.

[22] H. Ziar et al., "A comprehensive albedo model for solar energy applications: Geometric spectral albedo," Applied Energy, vol. 255, 2019.
[23] F. Vignola, J. Michalsky and T. Stoffel, "Chapter 9: Albedo," in Solar Radiation and Infrared Radiation Measurements, CRC Press, 2017, p. 193-204.

[24] W. Wiscombe and S. Warren, "A Model for the Spectral Albedo of Snow. Part 1," Journ. of Atmos. Sci., 1980.

[25] D. R. Myers, "Quantitative analysis of spectral impacts on silicon photodiode radiometers," in 40th ASES Conference, pp. 97-102, 2011.

[26] B. Stueve, "Field Albedo Measurements," in bifiPV Workshop, Amsterdam, 2019. 